\title{
Dispersal of Midges (Chironomidae, Diptera) on Terrestrial Area after the Emergence from Saline Lake Shira
}

\author{
Irina A. Vitkovskaya ${ }^{a}$, \\ Elena V. Borisova ${ }^{a}$ and Nadezhda N. Sushchik*a,b \\ ${ }^{a}$ Siberian Federal University \\ 79 Svobodny, Krasnoyarsk, 660041, Russia \\ ${ }^{b}$ Institute of Biophysics SB RAS \\ FRC "Krasnoyarsk Science Center SB RAS" \\ 50/50 Akademgorodok, Krasnoyarsk, 660036, Russia
}

Received 17.10.2017, received in revised form 15.11.2017, accepted 16.11.2017

We studied the number of midges (Chironomidae, Diptera) on the terrestrial area whereflows of organic matter and essential polyunsaturated fatty acids (PUFA) provided by the emergence of the amphibiotic insects from saline steppe Lake Shira were dispersed. Records of midge specimens captured on sticky traps showed that 50 and 95 percent of the emerged adults of the Glyptotendipes and Polypedilum genera occurred within 25-m and 100-m strips surrounding the lakeshore, respectively. The areas of these strips were calculated along with quantification of flows of chironomid biomass and essential PUFA per land area unit based on data of previously measured export. For the 25-m lake-surrounding strip, where $50 \%$ of midges swarmed, the annual import of dry biomass and PUFA accounted for $1.5 \mathrm{~g} \cdot \mathrm{m}^{-2}$ and $15 \mathrm{mg} \cdot \mathrm{m}^{-2}$, respectively. Further, the 100-m wide strip, where $95 \%$ of the midges were registered, got the annual flows of $0.7 \mathrm{~g}$ dry weight $\cdot \mathrm{m}^{-2}$ and $7.2 \mathrm{mg} P U F A \cdot \mathrm{m}^{-2}$. The calculated values of PUFA import were similar to measurements in relatively productive landscapes. The number of midges captured on the site located near the most productive lake part was the lowest among all the studied near-lake sites. This site of the lakeshore is part of a national preserve, where a great number of insectivorous birds live or stop. The lower abundance of swarming chironomids on this site was likely related to intensive consumption by terrestrial animals, i.e., birds, for obtaining necessary doses of essential compounds.

Keywords: emergence of amphibiotic insects, Chironomidae, dispersal distance, saline lake, South Siberia.

(C) Siberian Federal University. All rights reserved

This work is licensed under a Creative Commons Attribution-NonCommercial 4.0 International License (CC BY-NC 4.0).

* Corresponding author E-mail address: labehe@ibp.ru 


\title{
Распределение комаров-звонцов (Chironomidae, Diptera) на суше при вылете имаго из соленого озера Шира
}

\author{
И.А. Витковская ${ }^{a}$ Е.В. Борисова ${ }^{a}$, Н.Н. Сущик ${ }^{a, \tilde{0}}$ \\ ${ }^{a}$ Сибирский федеральный университет \\ Россия, 660041, Красноярск, пр. Свободный, 79 \\ ${ }^{6}$ Институт биофизики СО РАН \\ ФИЦ «Красноярский научныий иентр СО РАН» \\ Россия, 660036, Красноярск, Академгородок, 50/50
}

Исследовано распределение численности имаго комаров-звонцов (Chironomidae, Diptera) на суше, получающей потоки биомассы и незаменимых полиненасыщенных жирных кислот (ПНЖК) при вылете амфибионтных насекомых из соленого степного оз. Шира. В результате учетов имаго хирономид, попавших в липкие ловушки, установлено, что в пределах 25 м и 100 м от береговой линии озера конщентрируется 50 и 95 \% вылетевших особей родов Glyptotendipes и Polypediluт соответственно. Были рассчитаны размеры указанных наземных территорий u, с учетом дополнительных данных, выполнены количественные расчеты потоков биомассы хирономид и незаменимых ПНЖК на единииу их площади. Для 25-метровой прибрежной территории, где кониентрировалось 50 \% вылетевших особей, потоки составляли 1.5 г сухой массы $\cdot \mu^{-2}$ и 15 мг ПНЖК $\cdot \mu^{-2}$ в год. В свою очередь, 100-метровая прибрежная полоса, где оставалось $95 \%$ имаго хирономид, получала в год 0.7 г сухой массы $\cdot \mu^{-2}$ и 7.2 мг ПНЖК $\cdot \mu^{-2}$ соответственно. Полученная расчетная величина поступления ПНЖК на единииу площади наземной территории, окружающей оз. Шира, достигала значений, сопоставимых с весьма продуктивными ландшафтами. В ловушках, установленных вблизи наиболее продуктивной части озера, наблюдалась самая низкая численность хирономид по сравнению с прочими наземными участками. Эта часть побережья, имеющая природоохранный статус, населена значительным количеством насекомоядных птии, что, вероятно, обусловливает меньшее число роящзихся хирономид вследствие их интенсивного потребления наземными консументами для получения необходимых доз незаменимых биохимических веществ.

Ключевые слова: вылет амфибионтных насекомых, Chironomidae, дальность разлета, соленое озеро, Южная Сибирь.

\section{Введение}

В настоящее время вылет имаго амфибионтных насекомых из водоемов являет- ся одним из ключевых векторов переноса «субсидий» водной продукции в наземные экосистемы (Richardson et al., 2010). Комары- 
звонцы (Chironomidae, Diptera) представляют собой один из наиболее распространенных таксонов амфибионтных насекомых, обитающих в широком спектре климатических и экологических условий (Coler, Kondratieff, 1989). В некоторых водоемах эти организмы могут составлять до $99 \%$ численности бентоса (Ferrington et al., 2008). Так, во внутренних соленых водоемах и водотоках аридных ландшафтов именно хирономиды зачастую составляют основу зообентосного сообщества (Hart, Lovvorn, 2005; Zinchenko et al., 2014).

Вылетающие имаго хирономид повсеместно включаются в состав трофических цепей прилегающих наземных экосистем, нередко определяя периоды миграции и размножения наземных животных, а также пространственную структуру их популяций (Nakano, Murakami, 2001; Paetzold, Tockner, 2005; Gratton et al., 2008). Ряд видов беспозвоночных и позвоночных животных в период интенсивного вылета переходят на питание амфибионтными насекомыми, потребляя до 90 \% вылетевших имаго (Jackson, Fisher, 1986; Gray, 1993). Наряду с потоком общего органического углерода имаго вылетающих насекомых выносят на сушу специфические биохимические вещества, а именно длинноцепочечные полиненасыщенные жирные кислоты (ПНЖК) омега-3, которые синтезируются преимущественно водными продуцентами (Gladyshev et al., 2013). Эти вещества содержатся в основном в водной биологической продукции, включая биомассу амфибионтных насекомых, и, вместе с тем, являются незаменимыми компонентами диеты многих наземных всеядных животных. ПНЖК служат предшественниками нескольких серий липидных медиаторов и регулируют деятельность ряда организменных систем, включая развитие мозга и нервной ткани, а также функ- ционирование сердечно-сосудистой системы. Их источники в наземных трофических цепях практически отсутствуют, поэтому ПНЖК должны поступать к всеядным консументам суши с пищей водного происхождения.

Потоки общего органического углерода и незаменимых ПНЖК, выносимые с биомассой вылетающих насекомых, могут быть особенно важны для консументов аридных ландшафтов, где величины первичной продукции суши невелики (Millan et al., 2011). Для оценки роли амфибионтных насекомых в наземных трофических цепях необходимо знать их распространение по территории суши, граничащей с внутренними водами. Оценки расстояния разлета имаго хирономид от мест выплода очень разнятся: по некоторым данным, 50 \% особей популяции не улетают далее 13 м от береговой линии, однако есть данные о максимальном расстоянии разлета, составляющем 17 км (Muehlbauer et al., 2014). Возможно, такие различия объясняются тем фактом, что имаго некоторых таксонов способны улетать на значительное расстояние от мест выплода, в то время как другие ограничиваются лишь локальным распространением (Демина и др., 2013). Кроме того, дальность и направление разлета имаго могут определяться экологическими условиями наземного ландшафта (например, Petersen et al., 1999; Stenroth et al., 2015), и пока остаются малоизученными характеристиками.

Таким образом, целью настоящей работы было оценить распределение биомассы комаров-звонцов (Chironomidae, Diptera) на суше для уточнения площади наземной территории, получающей потоки органического углерода и ПНЖК в результате вылета хирономид, населяющих на личиночной стадии бентосное сообщество соленого степного оз. Шира. Были поставлены следующие за- 
дачи: определить численность имаго, находящихся на разном расстоянии от береговой линии; изучить особенности распределения имаго на разных берегах исследуемого озера.

\section{Материалы и методы}

\section{Район исследований}

Полевые измерения и наблюдения были выполнены на территории суши, прилегающей к крупному соленому озеру Шира (54³0' с.ш., 90¹2' в.д., Республика Хакасия, Южная Сибирь), где происходит разлет имаго хиромонид, личинки которых составляют значительную часть бентоса водоема. Подробная характеристика озера изложена в работах (Толомеев и др., 2018; Degermendzhy et al., 2010; Rogozin et al., 2017). Озеро является элементом степного ландшафта, особенности которого описаны в работах (Прокофьев, 1993; Природный комплекс..., 2011).

По данным А.П. Толомеева с соавторами (2018), в составе зообентоса оз. Шира присутствуют главным образом некто-бентосные рачки Gammarus lacustris (Amphipoda) и личинки Chironomidae (Diptera), тогда как представители прочих таксонов встречаются редко. Доминантами комплекса хирономид о3. Шира являются Glyptotendipes salinus (Michailova, 1987), Chironomus nigrifrons (Kieffer, 1913), Ch. halophilus (Linevich, 1971), Polypedilum bicrenatum (Kieffer, 1921). Имаго видов рода Glyptotendipes - крупные (до 1 см длиной) комары-звонцы с хорошо выраженными родовыми признаками, составляющие основу вылета в течение всего вегетационного сезона (Борисова и др., 2019), - были выбраны в качестве модельного объекта для учета дальности разлета имаго от мест выплода. Вместе с тем, в пробах учитывали также и иных представителей сем. Chironomidae. Таксономическую принадлежность комаровзвонцов устанавливали по препаратам ге- ниталий самцов (Определитель насекомых Дальнего Востока России, 1999; ContrerasLichtenberg, 1999; Langton, Pinder, 2007).

\section{Сбор проб}

Для учета дальности разлета имаго от мест выплода в июне и июле двух вегетационных сезонов напротив четырех станций в 2016 г. и двух станций в 2017 г., расположенных в озере согласно работе (Борисова и др., 2019, рис. 1), были установлены липкие ловушки на трансектах, перпендикулярных береговой линии озера. Вдоль трансекты точки учета дальности разлета располагали с помощью GPS навигатора на расстояниях 5, $10,15,20,25,50,100$ и 200 м от берега. Конструкция ловушки описана в работе (Smith et al., 2014) и представляет собой пластиковую чашку Петри $\left(\mathrm{S}_{\text {чашки }}=57 \mathrm{~cm}^{2}\right)$, на дно которой тонким слоем нанесен энтомологический клей (клей от грызунов и насекомых «Чистый дом»). Клей термо- и влагоустойчив, не имеет запаха и сохраняет эластичность в течение нескольких месяцев. На точках учета ловушки устанавливали на вертикальных шестах высотой $0.2,0.5$ и 1 м, на каждый шест крепили по 3 чашки, обращенные клейкой поверхностью в сторону воды, от воды и перпендикулярно береговой линии. Учет имаго насекомых, попавших в ловушки, проводили ежедневно в течение трех суток. Подсчет имаго хирономид вели в лаборатории с использованием бинокулярной лупы. В итоговых пробах суммировали особей, попавших в ловушки, расположенные на разной высоте и разных направлениях, т.е. суммарная площадь ловушки, находящейся на данной точке учета, составила $513 \mathrm{~cm}^{2}\left(\sim 0.05 \mathrm{~m}^{2}\right)$. Для расчета доли особей, сконцентрированных на точке трансекты, общая численность на точке (экз./сут) делили на сумму особей на всей трансекте (экз./сут). 


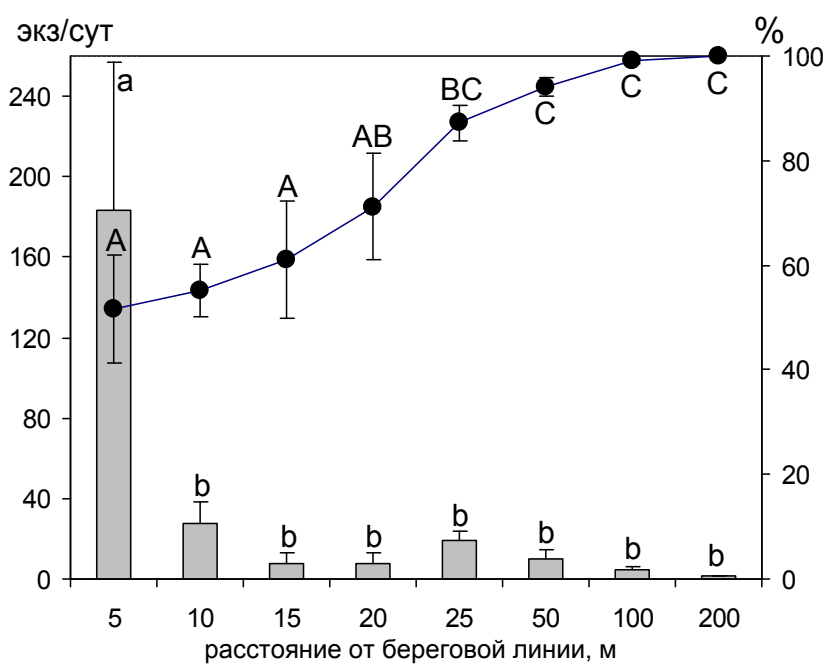

Рис. Суточные данные разлета хирономид от оз. Шира, усредненные по всем станциям и учетам 20162017 гг., n= 4-12. Столбцы - численность (среднее \pm стандартная ошибка) особей хирономид, пойманных в липкие ловушки на трансектах, перпендикулярных береговой линии оз. Шира. Кружки - относительная доля (в процентах от суммы особей, учтенных на трансекте за сутки, среднее \pm стандартная ошибка) хирономид, сосредоточенных в пределах данных расстояний от береговой линии. Средние значения, отмеченные одинаковыми буквами, достоверно не отличаются $(p<0.05)$ по post hoc LSD тесту Фишера

Fig. Daily data for the dispersal of chironomids emerged from Lake Shira, averaged for all stations and periods of the records, 2016-2017, $\mathrm{n}=4-12$. Bars - number of chironomid specimens (mean \pm standard error) captured on sticky traps placed along the transects perpendicular to Lake Shira shore. Circles - portion of specimens (percent of all specimens recorded on a transect per 24 hours) occurred within a given distance from the lakeshore. Mean values labelled with the same letter are not significantly different at $p<0.05$ according to post hoc LSD Fisher test

Расчеты дальности разлета и потоков органического вещества и ПНЖК, поступаюших на сушу с биомассой хирономид

Рассчитывали среднесуточные величины численности особей на точках учета разной удаленности, по данным разных станций и разных дат наблюдений. Достоверность влияния расстояния удаленности от воды и станций озера на численность хирономид оценивали с помощью однофакторного дисперсионного анализа и post hoc теста по критерию Фишера. На основании полученных распределений имаго определяли расстояния от береговой линии озера, в пределах которых находится более 50 и $95 \%$ особей на данной трансекте. Эти расстояния были далее использованы для расчета площади наземной территории, получающей потоки биомассы хирономид, вылетающих из озера. Соответствующие расчеты площадей были выполнены по спутниковым снимкам Google Earth (https:// www.google.ru/maps) с использованием программы ImageJ 1.46.

Для расчетов потоков биомассы хирономид на единицу площади суши были использованы величины валового годового вылета со всей акватории озера (Борисова и др., 2019), которые были разделены на площади суши, получающие 50 \% и 95 \% вылетающих особей. Для расчета потока ПНЖК, приходящегося на единицу площади суши, годовой поток биомассы имаго на сушу был умножен на среднее содержание ПНЖК в 
биомассе данных видов (Makhutova et al., 2017).

Суточное распределение численности комаров-звонцов, попавших в липкие ловушки, сравнивали с суточными потоками биомассы хирономид с единицы площади акватории (Борисова и др., 2019), наблюдаемыми на близлежащих станциях в одни и те же периоды.

\section{Результаты и обсуждение}

Подавляющее большинство имаго хирономид, попадавших в липкие ловушки, относились к родам Glyptotendipes либо Polypedilum ( $95 \%$ от общей численности). Представители рода Chironomus составили весьма малую часть уловов липких наземных ловушек, подобно уловам водных ловушек, установленных на озере (Борисова и др., 2019).

Распределение численности хирономид в ловушках, размещенных вдоль трансект, представляло собой экспоненциально убывающую кривую (рис.). Такое распределение биомассы вылетевших амфибионтных насекомых, включая хирономид, на прилегающей к водному объекту территории отмечено во многих работах (например, Gratton, Vander Zanden, 2009; Muehlbauer et al., 2014). Сравнение численности (экз./сут) имаго в ловушках и процентной доли имаго, находящихся в пределах данного расстояния от озера (\% от суммы всех особей, учтенных на трансекте), с помощью однофакторного дисперсионного анализа показало, что удаленность от воды достоверно влияла на эти показатели $(F=3.23$, $p<0.05$; и $F=14.5, p<0.05$ соответственно при $\left.d f_{1}=7, d f_{2}=71\right)$. Очевидно, что уже в пределах 5 метров от берега концентрировалось более 50 \% имаго, отмеченных на трансекте (рис.). Вместе с тем, относительная доля особей, попавших в ловушки, расположенные на точ- ках в пределах 20 метров от берега (50-65 \%), статистически достоверно не отличалась. Выявлены статистически достоверные различия в нарастающем проценте численности хирономид между точками, расположенными на расстоянии до 20 м и далее 50 м от берега. Между точками, удаленными на 25 метров и далее, статистически достоверных отличий в суммарной доле имаго (87-100 \%) выявлено не было. При этом свыше 95 \% особей, учтенных на трансекте, было сосредоточено в пределах 100 метров от берега (рис.).

Исходя из полученного распределения нарастающего процента особей, расстояния 25 и 100 метров от береговой линии были выбраны как границы наземной территории, где сосредоточено $50 \%$ и $95 \%$ численности имаго хирономид, вылетевших из озера. Площади этих наземных территорий составили

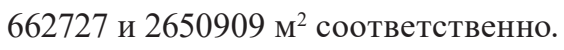

Согласно обобщенной оценке, среднее расстояние разлета хирономид от мест выплода для 50 \% особей популяции составляет 13.3 м. Полученное нами расстояние разлета половины вылетевших имаго из оз. Шира вполне сопоставимо с вышеуказанной средней оценкой. Известно, что имаго некоторых представителей двукрылых насекомых способны улетать на значительное расстояние от мест выплода из водоема, в то время как другие виды ограничиваются локальным распределением и роением вблизи водоема или водотока. При этом разные виды с одними и теми же морфологией крыла и размерами тела могут использовать как активный полет, так и пассивное распространение при помощи ветра (Демина и др., 2013). В летний сезон 2017 г. мы наблюдали особенности разлета доминантов профундали оз. Шира - представителей p. Chironomus. Эти хирономиды отличались заметно большими размерами тела по сравнению с особями Glyptotendipes и 
Polypedilum и, очевидно, обладали развитыми летательными способностями. После выплода имаго Chironomus поднимались на несколько метров над поверхностью воды и удалялись на значительные расстояния от берега (по наблюдениям на 300 и более метров) в поисках возвышенностей, пригодных для роения. Эти наблюдения объясняют практически полное отсутствие особей Chironomus в липких наземных ловушках, установленных на небольших высотах (0.2-1 м от поверхности почвы) в нижней части долины озера.

Общая численность особей хирономид на трансектах, расположенных вблизи разных станций (берегов) озера, усредненная по данным разных месяцев и вегетационных сезонов, статистически достоверно не различалась (табл.). При этом наблюдалась значительная внутри- и межсезонная вариабельность численности хирономид в ловушках всех станций, очевидно, обусловленная локальными пиками вылета имаго из водоема. В связи с этим сравнение численности имаго между станциями проведено по наиболее полным данным в отдельные сезоны 2016 г. (табл.). В июне 2016 г. численность хирономид, сосредоточенных на трансекте близ станции 3, была достоверно меньше, а численность хирономид на станции 4 достоверно больше значений на трансектах близ других станций. В июле 2016 г. также наблюдалась тенденция к более низкой численности на станции 3 , хотя достоверных различий выявлено не было (табл.). Очевидно, что распределение численности особей в наземных ловушках разных станций не соответствовало среднесезонной интенсивности вылета по акватории (Борисова и др., 2019). Наибольшая величина суточного вылета, в среднем по сезону, наблюдалась на станции 3 , тогда как суточная численность особей, пойманных в наземные ловушки, расположенные на этой станции, была наименьшей (табл.).

Необходимо отметить, что часть наземной экосистемы, прилегающая к озеру в районе станции 3, относится к территории

Таблица. Численность (среднее \pm стандартная ошибка) особей имаго хирономид, пойманных за сутки в липкие ловушки на трансектах станций оз. Шира в разные периоды учетов 2016 и 2017 гг. $F$ значение критерия Фишера в однофакторном дисперсионном анализе сравнения станций, $p-$ уровень статистической доверительной вероятности, $\mathrm{n}$ - число проб на трансекте за период наблюдений. Значения, отмеченные одинаковыми буквами, достоверно не отличаются $(p<0.05)$ по post hoc LSD тесту Фишера

Table. Number of chironomid adults (mean \pm standard error) captured on sticky traps per 24 hours on transects near Lake Shira in various periods of 2016-2017. $F$ - Fisher test values, $p$ - level of statistical significance in ANOVA compared lake stations, $\mathrm{n}$ - number of samples for a transect per a period. Means labelled with the same letter are not significantly different at $p<0.05$ according to post hoc LSD Fisher test

\begin{tabular}{|c|c|c|c|c|c|c|}
\hline & ст. 1 & ст. 2 & ст. 3 & ст. 4 & $F$ & $p$ \\
\hline \multicolumn{7}{|c|}{ июнь-июль 2016-2017 гг. } \\
\hline $\mathrm{n}$ & 10 & 6 & 6 & 10 & & \\
\hline экз $\cdot$ сут $^{-1}$ & $227 \pm 60$ & $340 \pm 89$ & $107 \pm 40$ & $362 \pm 103$ & 1.75 & $>0.05$ \\
\hline \multicolumn{7}{|c|}{ июнь 2016} \\
\hline $\mathrm{n}$ & 3 & 3 & 3 & 3 & & \\
\hline экз $\cdot$ сут $^{-1}$ & $455 \pm 42^{\mathrm{A}}$ & $519 \pm 53^{\mathrm{A}}$ & $194 \pm 20^{\mathrm{B}}$ & $810 \pm 79^{C}$ & 22.70 & $<0.001$ \\
\hline \multicolumn{7}{|c|}{ июль 2016} \\
\hline $\mathrm{n}$ & 3 & 3 & 3 & 3 & & \\
\hline эКз $\cdot$ сут $^{-1}$ & $246 \pm 56$ & $162 \pm 72$ & $20 \pm 3$ & $214 \pm 54$ & 3.55 & $>0.05$ \\
\hline
\end{tabular}


Хакасского государственного заповедника, на которой охраняются многие виды птиц (Природный комплекс.., 2011). Предпочтение птицами данного участка побережья в качестве местообитания или места стоянки среди прочих факторов (характерная растительность, отсутствие беспокойства и т.д.) может быть обусловлено значительным потоком на сушу водной продукции в виде имаго амфибионтных насекомых. Интенсивное потребление птицами в итоге может приводить к снижению численности роящихся здесь имаго. Многие авторы отмечают значительную роль хирономид в питании насекомоядных птиц (Демина и др., 2013; Gray, 1993; Nakano, Murakami, 2001; MacKenzie, Kaster, 2004), что подтверждает полученные нами результаты о распределении численности имаго.

С использованием полученных ранее данных о суммарном годовом экспорте биомассы с акватории озера, прежде всего за счет таксонов родов Glyptotendipes и Polypedilum, составляющем 6.9 тонн (Борисова и др., 2019), и содержании ПНЖК в биомассе, 2.9 мг $\cdot \Gamma^{-1}$ (Makhutova et al., 2017), были рассчитаны величины потоков биомассы хирономид и незаменимых ПНЖК на единицу площади суши. Для прилегающей наземной территории (25-метровой прибрежной полосы), где концентрируется 50 \% вылетевших особей хирономид, поток составлял 1.5 г сухой массы $\cdot \mathrm{M}^{-2}$ и 15 мг ПНЖК $\cdot$ м $^{-2}$ в год. В свою очередь, территория, где находилось $95 \%$ особей вылетевших хирономид (т.е. 100-метровая прибрежная полоса), получала в год 0.7 г сухой массы $\cdot \mathrm{M}^{-2}$ и 7.2 мг ПНЖК $\cdot \mathrm{M}^{-2}$. Согласно глобальной оценке, поток незаменимых длинноцепочечных ПНЖК на единицу площади суши за счет вылета амфибионтных насекомых колеблется в пределах 2.5-11.8 мг $\cdot \mathrm{M}^{-2} \cdot$ год ${ }^{-1}$ (Gladyshev et al., 2009). Наши расчетные величины хорошо соответствовали указанным пределам. Однако глобальные расчеты не учитывали экспоненциального затухания потоков по мере удаления от береговой линии водного объекта, характерного для вылета многих амфибионтных насекомых, включая хирономид (Delettre, Morvan, 2000; Gratton, Vander Zanden, 2009; Muehlbauer et al., 2014). Martin-Creuzburg с соавторами (2017) рассчитали поток ПНЖК на сушу с учетом такого снижения в пределах 100-метровой полосы, по вылету амфибионтных насекомых из небольшого озера на юге Германии, составивший 66 мг $\cdot \mathrm{M}^{-2} \cdot$ год $^{-1}$. По сравнению с данной величиной поток ПНЖК на единицу площади 100-метровой прибрежной полосы оз. Шира был меньше почти на порядок. Значительные различия определяются большим разнообразием таксонов амфибионтных насекомых и более высокими величинами годового вылета для озера в Германии (Martin-Creuzburg et al., 2017) относительно соответствующих показателей вылета хирономид из оз. Шира (Борисова и др., 2019).

\section{Заключение}

Таким образом, в прибрежной части наземной территории, окружающей оз. Шира полосой шириной 25 метров, расчетная величина потока ПНЖК на единицу площади за счет вылета имаго хирономид достигала значений, сопоставимых с весьма продуктивными ландшафтами (Gladyshev et al., 2009). Очевидно, что вылет имаго хирономид может стимулировать наземных консументов данного ландшафта к питанию в прибрежной полосе для получения необходимых доз незаменимых биохимических веществ с пищей водного происхождения (например, Twining et al., 2016). Относительно меньшая численность роящихся хирономид на прибрежном участке вблизи самой продуктивной части озера, включенном в состав природоохран- 
ной территории, может свидетельствовать об

ными птицами и другими наземными консуинтенсивном потреблении имаго насекомояд-

ментами, чья численность на территории заповедника может быть более высокой, чем на других участках, прилегающих к озеру.

Работа была поддержана совместным грантом РФФИ - ККФПНиНТД 16-44240421p_a, грантом НШ-9249.2016.5 Совета по грантам Президента Российской федерации по государственной поддержке ведущих научных икол, проектом Сибирского отделения Российской академии наук № II.2П/VI.51-1, а также Государственным заданием в рамках программы фундаментальных исследований РФ, тема № 51.1.1.

\section{Список литературы}

Борисова Е.В., Толомеев А.П., Дроботов А.В., Сущик Н.Н. (2019) Вылет хирономид (Chironomidae, Diptera) из соленого озера как источник органического углерода и незаменимых биохимических веществ для аридных экосистем юга Сибири. Журнал Сибирского федерального университета. Биология, 12(2): 196-215 [Borisova E.V., Tolomeev A.P., Drobotov A.V., Sushchik N.N. (2019) Emergence of midges (Chironomidae, Diptera) from a saline lake as a source of organic matter and essential biochemical compounds for arid ecosystems in South Siberia. Journal of Siberian Federal University. Biology, 12(2): 196-215 (in Russian)]

Демина И.В., Ермохин М.В., Полуконова Н.В. (2013) Структура и динамика потоков вещества и энергии, формируемых при вылете имаго гетеротопных насекомых через границу «вода - воздух» пойменных озер р. Волга. Известия Саратовского университета. Новая серия. Серия Химия. Биология. Экология, 13(3): 85-93 [Demina I.V., Ermochin M.V., Polukonova N.V. (2013) Structure and dynamics of matter and energy flows by heterotopic insects imago emergence across the "water-air" surface of lakes in Volga river floodplain. Izvestiya of Saratov University. Series: Chemistry. Biology. Ecology [Izvestiya Saratovskogo universiteta. Seria Khimia, Biologia, Ecologia], 13(3): 85-93 (in Russian)]

Определитель насекомых Дальнего Востока России (1999) Двукрылые и блохи. Т. VI. Ч. 1. Владивосток, Дальнаука, 665 с. [Keys to the insects of the Russian Far East (1999) Diptera and Siphonaptera. Vol. VI. Part 1. Vladivostok, Dalnauka, 665 p. (in Russian)]

Природный комплекс и биоразнообразие участка «Озеро Шира» заповедника «Хакасский» (2011) Непомнящий В.В. (ред.) Абакан, Хакасское книжное издательство, 420 с. [Native community and biodiversity of "Lake Shira" area from the "Khakassian" natural reservation. Nepomnyashchii V.V. (ed.) Khakassian Book Press, 420 p. (in Russian)]

Прокофьев С.М. (1993) Природа Хакасии: Пособие. Абакан, Хакасское книжное издательство [Prokof'ev S.M. (1993) Nature of Khakasia: manual. Abakan, Khakassian Book Press (in Russian)]

Толомеев А.П., Шулепина С.П., Махутова О.Н., Агеев А.В., Дроботов А.В., Сущик Н.Н. (2018) Характеристика таксономического состава и биомассы зообентоса соленого озера Шира: изменения, произошедшие за 65 лет. Журнал Сибирского федерального университета. Биология, 11(4): 367-383 [Tolomeev A.P., Shulepina S.P., Makhutova O.N., Ageev A.V., 
Drobotov A.V., Sushchik N.N. (2018) Taxonomic composition and biomass of zoobenthos in saline Lake Shira: shifts that happened in 65 years. Journal of Siberian Federal University. Biology, 11(4): 367-383 (in Russian)]

Coler B.G., Kondratieff B.C. (1989) Emergence of Chironomidae (Diptera) from a delta-swamp receiving thermal effluent. Hydrobiologia, 174(1): 67-77

Contreras-Lichtenberg R. (1999) Revision der westpaläarktischen Arten des Genus Glyptotendipes Kieffer, 1913 (Insecta: Diptera: Chironomidae). Teil 1: Subgenus Phytotendipes Goetghebuer, 1937. Annalen des Naturhistorischen Museums in Wien, 101B: 359-403

Degermendzhy A.G., Zadereev E.S., Rogozin D.Yu., Prokopkin I.G., Barkhatov Y.V., Tolomeev A.P., Khromechek E.B., Janse J.H., Mooij W.M., Gulati R.D. (2010) Vertical stratification of physical, chemical and biological components in two saline lakes Shira and Shunet (South Siberia, Russia). Aquatic Ecology, 44(3): 619-932

Delettre Y.R., Morvan N. (2000) Dispersal of adult aquatic Chironomidae (Diptera) in agricultural landscapes. Freshwater Biology, 44(3): 399-411

Ferrington L.C., Masteller E.C., Santiago-Blay J.A. (2008) Comparison and significance of chironomidae emergence from Lake Erie and Presque bay, Erie, Pennsylvania, U.S.A. Boletim do Museu Municipal do Funchal (História Natural), 13: 21-28

Gladyshev M.I., Arts M.T., Sushchik N.N. (2009) Preliminary estimates of the export of omega-3 highly unsaturated fatty acids (EPA+DHA) from aquatic to terrestrial ecosystems. Lipids in aquatic ecosystems. Arts M.T., Brett M.T., Kainz M.J. (eds.) Springer, N.Y., p. 179-210

Gladyshev M.I., Sushchik N.N., Makhutova O.N. (2013) Production of EPA and DHA in aquatic ecosystems and their transfer to the land. Prostaglandins and Other Lipid Mediators, 107: 117-126

Gratton C., Donaldson J., Vander Zanden M.J. (2008) Ecosystem linkages between lakes and the surrounding terrestrial landscape in Northeast Iceland. Ecosystems, 11(5): 764-774

Gratton C., Vander Zanden M.J. (2009) Flux of aquatic insect productivity to land: comparison of lentic and lotic ecosystems. Ecology, 90(10): 2689-2699

Gray L.J. (1993) Responses of insectivorous birds to emerging aquatic insects in riparian habitats of a tallgrass prairie stream. American Midland Naturalist, 129(2): 288-300

Hart E.A., Lovvorn J.R. (2005) Patterns of macroinvertebrate abundance in inland saline wetlands: a trophic analysis. Hydrobiologia, 541: 45-54

Jackson J.K., Fisher S.G. (1986) Secondary production, emergence, and export of aquatic insects of a Sonoran desert stream. Ecology, 67(3): 629-638

Langton P.H., Pinder L.C.V. (2007) Keys to the adult male Chironomidae of Britain and Ireland. Freshwater Biological Association Publishing, Ambleside, 239 p.

MacKenzie R.A., Kaster J.L. (2004) Temporal and spatial patterns of insect emergence from a Lake Michigan coastal wetland. Wetlands, 24(3): 688-700

Makhutova O.N., Borisova E.V., Shulepina S.P., Kolmakova A.A., Sushchik N.N. (2017) Fatty acid composition and content in chironomid species at various life stages dominating in a saline Siberian lake. Contemporary Problems of Ecology, 10(3): 230-239

Martin-Creuzburg D., Kowarik C., Straile D. (2017) Cross-ecosystem fluxes: Export of polyunsaturated fatty acids from aquatic to terrestrial ecosystems via emerging insects. Science of the Total Environment, 577: 174-182 
Millan A., Velasco J., Gutierrez-Canovas C., Arribas P., Picazo F., Sanchez-Fernandez D., Abellan P. (2011) Mediterranean saline streams in southeast Spain: What do we know? Journal of Arid Environments, 75(12): 1352-1359

Muehlbauer J.D., Collins S.F., Doyle M.W., Tockner K. (2014) How wide is a stream? Spatial extent of the potential "stream signature" in terrestrial food webs using meta-analysis. Ecology, 95(1): $44-55$

Nakano S., Murakami M. (2001) Reciprocal subsidies: Dynamic interdependence between terrestrial and aquatic food webs. Proceedings of the National Academy of Sciences of the United States of America, 98(1): 166-170

Paetzold A., Tockner K. (2005) Effects of riparian arthropod predation on the biomass and abundance of aquatic insect emergence. Journal of North American Benthological Society, 24(2): 395-402

Petersen I., Winterbottom J.H., Orton S., Friberg N., Hildrew A.G., Spiers D.C., Gurney W.S.C. (1999) Emergence and lateral dispersal of adult Plecoptera and Trichoptera from Broadstone Stream, UK. Freshwater Biology, 42(3): 401-416

Richardson J.S., Zhang Y., Marczak L.B. (2010) Resource subsidies across the land-freshwater interface and responses in recipient communities. River Research and Applications, 26(1): 55-66

Rogozin D., Zadereev E., Prokopkin I., Tolomeev A., Barkhatov Y., Khromechek E., Degermendzhi N., Drobotov A., Degermendzhi A. (2017) Comparative study of the stability of stratification and the food web structure in the meromictic lakes Shira and Shunet (South Siberia, Russia). Ecology of meromictic lakes. Gulati R.D., Zadereev E., Degermendzhi A. (eds.) Springer International Publishing, N.Y., p. 89-124

Smith J.T., Kennedy T.A., Muehlbauer J.D. (2014) Building a better sticky trap: description of an easy-to-use trap and pole mount for quantifying the abundance of adult aquatic insects. Freshwater Science, 33(3): 972-977

Stenroth K., Polvi L.E., Faltstrom E., Jonsson M. (2015) Land-use effects on terrestrial consumers through changed size structure of aquatic insects. Freshwater Biology, 60(1): 136-149

Twining C.W., Brenna J.T., Lawrence P., Shipley J.R., Tollefson T.N., Winkler D.W. (2016) Omega-3 long-chain polyunsaturated fatty acids support aerial insectivore performance more than food quantity. Proceedings of the National Academy of Sciences of the United States of America, 113(39): 10920-10925

Zinchenko T.D., Gladyshev M.I., Makhutova O.N., Sushchik N.N., Kalachova G.S., Golovatyuk L.V. (2014) Saline rivers provide arid landscapes with a considerable amount of biochemically valuable production of chironomid (Diptera) larvae. Hydrobiologia, 722(1): 115-128 